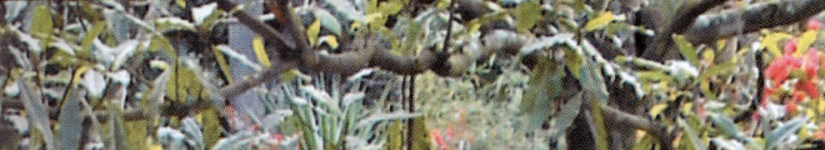

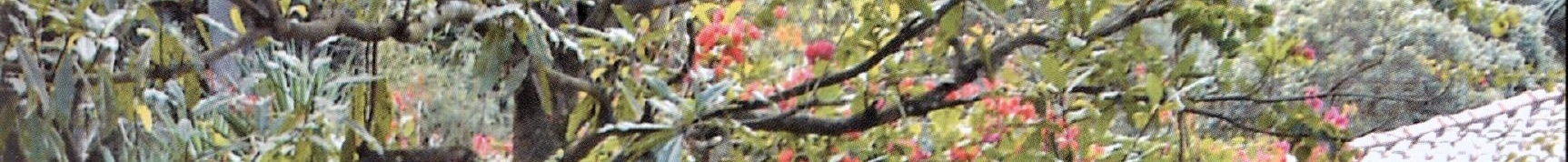

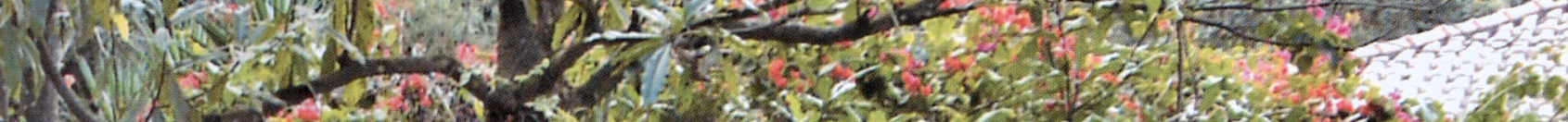
150 (1)

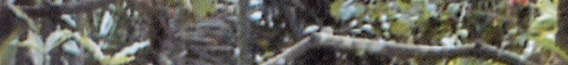

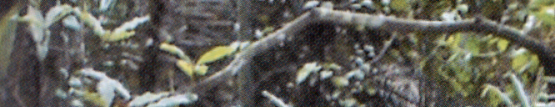
3.

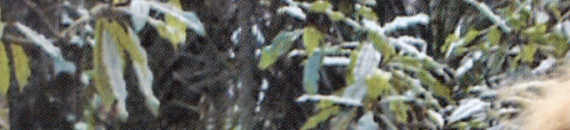

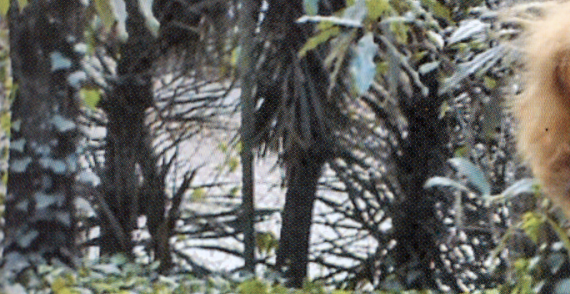

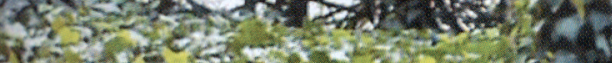

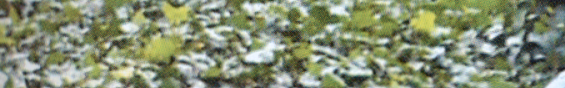

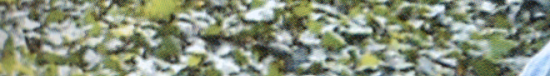

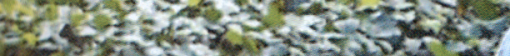

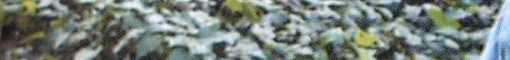

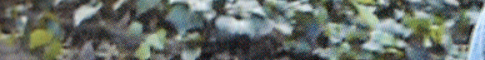
40 $\cos (x)$

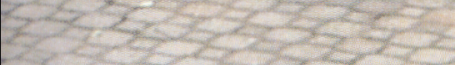
(2) s 3 (2)

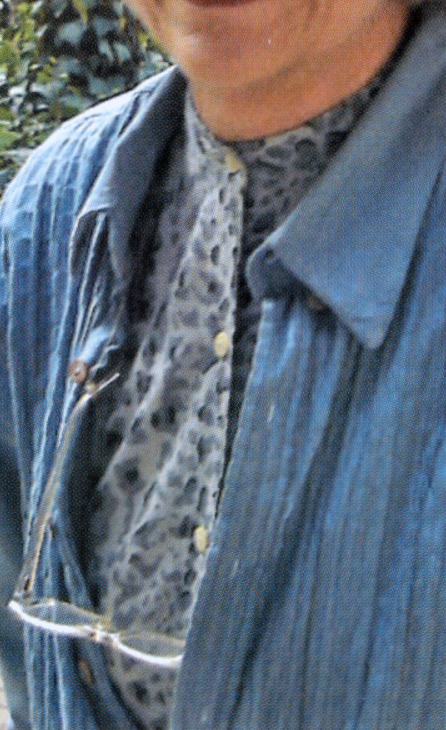

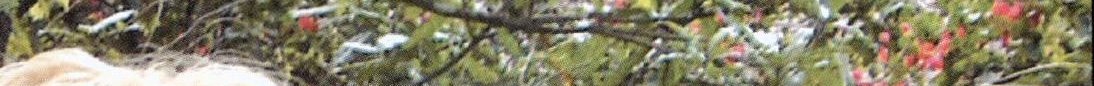
Par a

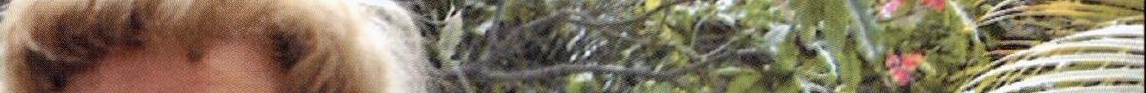
10. (a) (a) 2. (S) 15 2. .
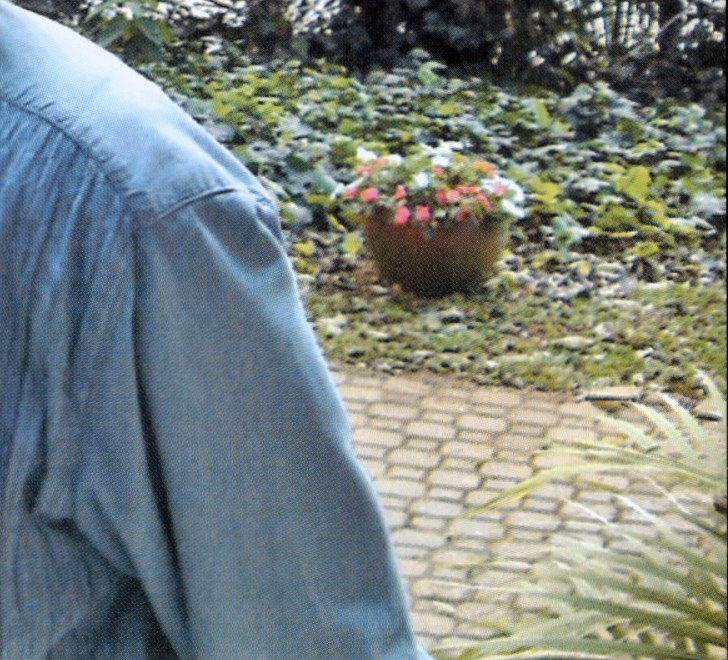

MIRANDA MAGNOLI...

Nestor Goulart Reis Filho

Professor titular da Faculdade de Arquitetura e

Urbanismo da Universidade de São Paulo (FAUUSP). 
| 


\section{MIRANDA MAGNOLI...}

Conheci Miranda Maria Esmeralda Martinelli, hoje Magnoli, no início do curso. Quando entramos, a FAU era pequena. Tinha apenas três turmas; a nossa era a quarta. Éramos, no total, cerca de 120 alunos, sendo 28 no primeiro ano de 1951. Na época, o ambiente era de cordialidade entre alunos de todas as turmas. Havia uma mesa no centro do saguão, ao redor da qual sentávamos, nos intervalos de aula, conversando sobre todos os assuntos que tivessem interesse para arquitetura e urbanismo.

Havia poucas moças, de uma a três por ano. Eram em geral filhas de europeus, com preocupações que ainda não haviam chegado às famílias brasileiras. Miranda era uma delas. Rapidamente ficamos amigos. Fizemos sempre parte de grupos de estudos, de grupos de atividades culturais do GFAU e discussões políticas. A semelhança de interesses culturais e o hábito de falar o que pensamos sobre os assuntos políticos sempre nos aproximaram.

O pai de Miranda, engenheiro italiano, da mesma cidade que o líder socialista Matteoti, assassinado pela polícia de Mussolini, mudou-se para o Brasil com a família, para que os filhos não fossem criados sob a facismo. Fiquei amigo de todos: dela, dos pais e do irmão, Dante Martinelli, como hoje sou amigo do filho, Demétrio Magnolli.

Durante o curso, participávamos de visitas a obras de arquitetura tradicional e modernas, participávamos de visitas às cidades históricas, ao Rio de Janeiro e ao Nordeste. Na linha de pensamento de Lúcio Costa, procurávamos conhecer as obras mais simples do passado e as mais complexas, dos arquitetos modernos. Até hoje não consigo entender o que levou alguns de nós a procurar estabelecer uma relação mais clara entre arquitetura e planejamento, no passado, como no presente. Mas essa orientação, que marcaria mais tarde os trabalhos de Miranda, já estava presente, naquele tempo. Participando de trabalhos com o pai e o irmão, ao entrar na FAU, Miranda já trazia uma experiência de organização e apresentação de trabalhos na prancheta, de nível profissional, que a distinguia entre os colegas. Ao mesmo tempo, conseguia apresentar desempenho mais lúcido em termos estruturais, nos trabalhos propostos em resistência dos materiais, por nosso muito caro mestre Augusto Carlos de Vasconcellos ou pelo igualmente estimado Figueiredo Ferraz, nesse tempo um jovem livre-docente da cátedra de Concreto Armado.

São Paulo iniciava seus passos como centro cultural e os alunos da FAU acompanhavam de perto as novidades: os dois museus de arte recém-criados (o MASP e o MAM), as primeiras bienais, que nos trouxeram Walter Gropius, e vários outros líderes do movimento moderno (alguns deles foram levados à FAU), o Teatro Brasileiro de Comédia, com alto nível profissional, a Vera Cruz, com o início do cinema de produção regular, o teatro Cultura Artística com seus concertos, com sua sede projetada por Rino Levi e as obras de nossos outros professores: Villanova Artigas, Knesse de Mello, Hélio Duarte, Plínio Crocce, Icaro de Castro Mello, Abelardo de Souza, com quem trabalhava nosso colega Maitrejean. Em 1954 juntavam-se a essa lista as obras de Oscar Niemeyer em São Paulo, do edifício Eiffel ao Copan e às do lbirapuera, onde trabalhou uma equipe numerosa de arquitetos paulistas e cariocas.

Nós visitávamos tudo. Como se fosse pouco, nos horários de almoço, durante quase uma hora, ouvíamos música erudita na sala dos fundos do GFAU, antes de voltar às pranchetas. 
Talvez seja bom lembrar que nesse tempo desenvolvíamos nossos projetos nas pranchetas da FAU, durante muitas horas por semana. Era assim que podíamos reconhecer as qualidades dos trabalhos de alguns de nossos colegas, como era o caso de Miranda, a qual, no final do curso, passou a estagiar com Roberto Coelho Cardozo, definindo sua carreira como paisagista.

Na segunda metade das décadas 1950/1960 fomos ambos contratados como assistentes e voltamos à FAU para trabalhar como docentes; Miranda, como seria de esperar, na área de Paisagismo. Nessas condições, continuei a acompanhar os trabalhos de minha colega, já então uma paisagista reconhecida no meio profissional.

Em 1972 Miranda defendeu sua tese de doutorado. Nos anos seguintes decidiu entrar em regime de tempo integral e criou uma equipe de pesquisa, dando origem ao grupo de disciplinas de Paisagismo, no Departamento de Projeto.

Nesse trabalho de institucionalização da pesquisa em sua área, adołou uma diretriz que marca seu trabalho entre os paisagistas: a vinculação clara do Paisagismo com o Planejamento Urbano. Essa talvez seja a grande novidade: a relação entre o projeto urbanístico e o meio ambiente, com uma perspectiva específica de organização da paisagem.

Essa diretriz é, sem dúvida, coerente com seus ideais de juventude, que relacionavam sempre os espaços arquitetônicos ao urbano, como decorrência de uma preocupação social, de relação organizada entre o público e o privado, entre o projeto de conjunto e o projeto da parte.

Há alguns anos Miranda se aposentou, para voltar ao exercício profissional, no qual sempre se destacou. Mas deixou seus antigos colaboradores com as qualificações universitárias adequadas para dar continuidade ao que criou.

A área do Paisagismo tem hoje uma presença forte na FAU, com um significativo trabalho realizado, com um laboratório, uma revista e numerosas disciplinas. Por isso mesmo, é oportuno registrar o papel desempenhado por minha colega e amiga, na construção desse quadro. Para nós, que começamos na mesma época, a origem de tudo parece estar no passado, na mesa no centro do saguão da Vila Penteado, nas viagens e visitas a obras, no trabalho, muito trabalho realizado ao longo dessas décadas.

É um prazer saber que seus continuadores registram publicamente seu reconhecimento pela importância desse trabalho, homenageando Miranda Martinelli Magnoli e dando continuidade a tudo o que criou.

\author{
Nestor Goulart Reis Filho \\ Setembro 2006
}

